\title{
Guidewire-assisted technique for gastroscope insertion through stricture of Zenker's diverticulum for esophageal endoscopic submucosal dissection
}

A 65-year-old asymptomatic man underwent screening esophagogastroduodenoscopy before treatment for tongue cancer. Standard gastroscopes (GIFH290Z and GIF-H290; Olympus) could not pass through the cervical esophagus. However, an ultra-slim gastroscope (GIFXP290N; Olympus) was able to pass through and revealed a Zenker's diverticulum ( Fig.1 a, b). A superficial esophageal cancer was detected in the upper thoracic esophagus ( $\bullet$ Fig. 2). Biopsy specimens from the lesion showed squamous cell carcinoma. The patient opted for endoscopic submucosal dissection (ESD), which requires standard gastroscope insertion ( $\vee$ Video $\mathbf{1}$ ).

An ultra-slim gastroscope was introduced through the stricture of the Zenker's diverticulum. A 0.035-inch guidewire (Hydra Jagwire; Boston Scientific Corporation, Marlborough, Massachusetts, USA) was advanced and kept in the stomach through the accessory channel of the ultra-slim gastroscope after its withdrawal (> Fig.3). Subsequently, a straight catheter was placed in the accessory channel of the standard gastroscope. The guidewire was inserted from the tip of the gastroscope through the catheter in a retrograde fashion. This procedure allowed for scope exchange. The standard gastroscope passed the stricture of the diverticulum through the guidewire, but the gastroscope was not able to pass through even with an endoscopic cap. Thus, ESD was performed without the endoscopic cap using ESD knives (Dual Knife J and IT-knife nano; Olympus). The lesion was successfully resected en bloc uneventfully (> Fig. 4, > Fig.5).

Zenker's diverticulum is a rare anatomic defect characterized by herniation of the mucosa and submucosa through the Killian triangle located in the esophageal cervical region. They are usually asymptomatic, but dysphagia, aspiration pneumonia, and stricture may occur as the diverticulum expands. Endoscopic diver-
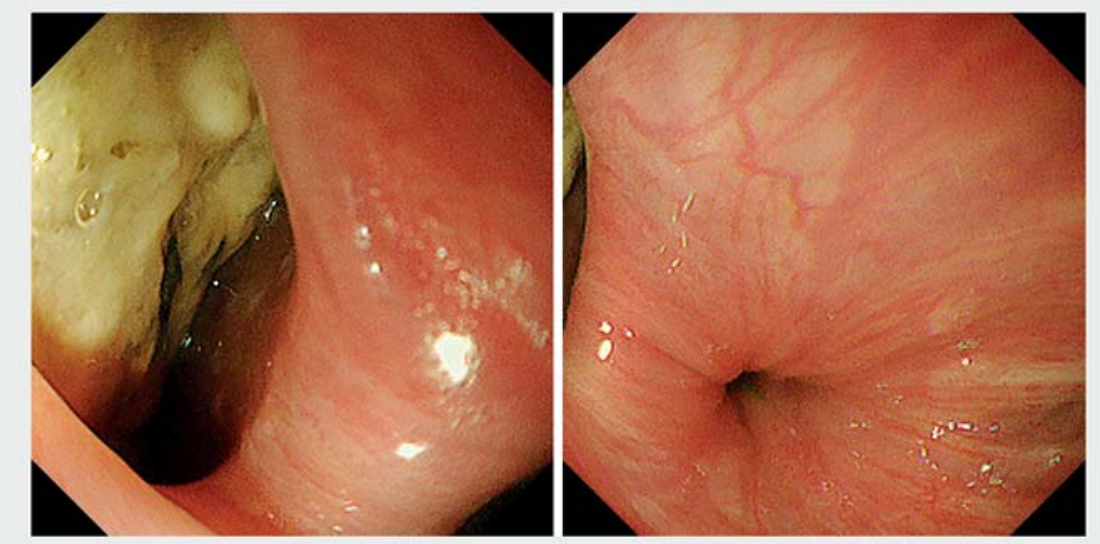

- Fig. 1 a, b Zenker's diverticulum on the left wall of the cervical esophagus.

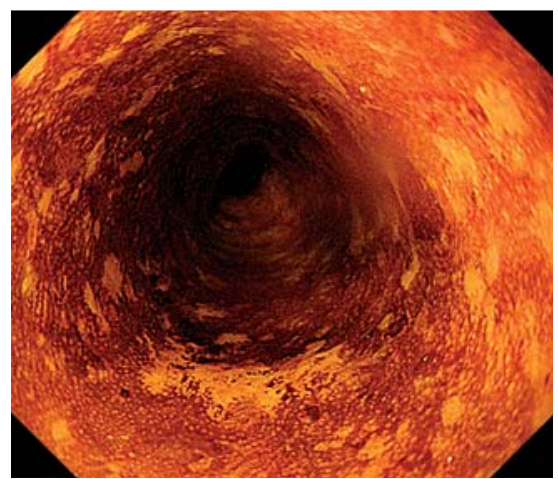

Fig. 2 A slightly elevated iodine-unstained lesion in the esophagus on the anal side of the Zenker's diverticulum.

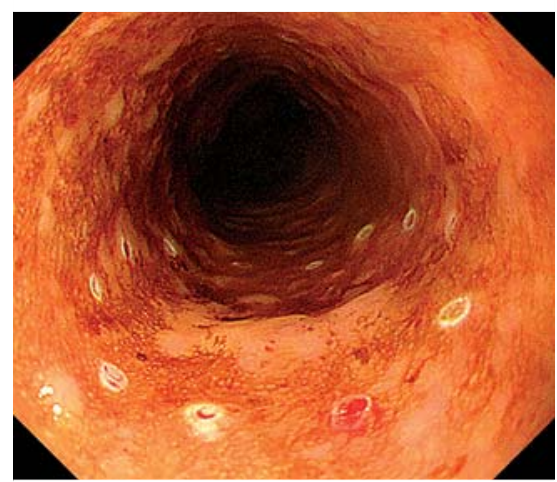

- Fig.4 Endoscopic peripheral markings were performed around the lesion.

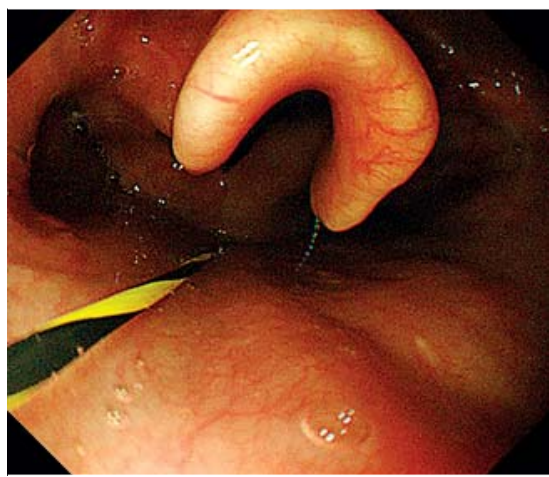

- Fig. 3 A 0.035-inch guidewire was advanced and kept in the stomach through the accessory channel of the ultra-slim gastroscope and the gastroscope withdrawn.

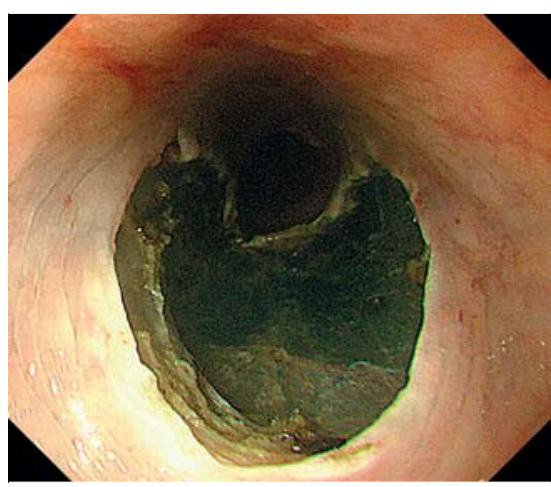

- Fig. 5 The lesion was resected en bloc uneventfully. 


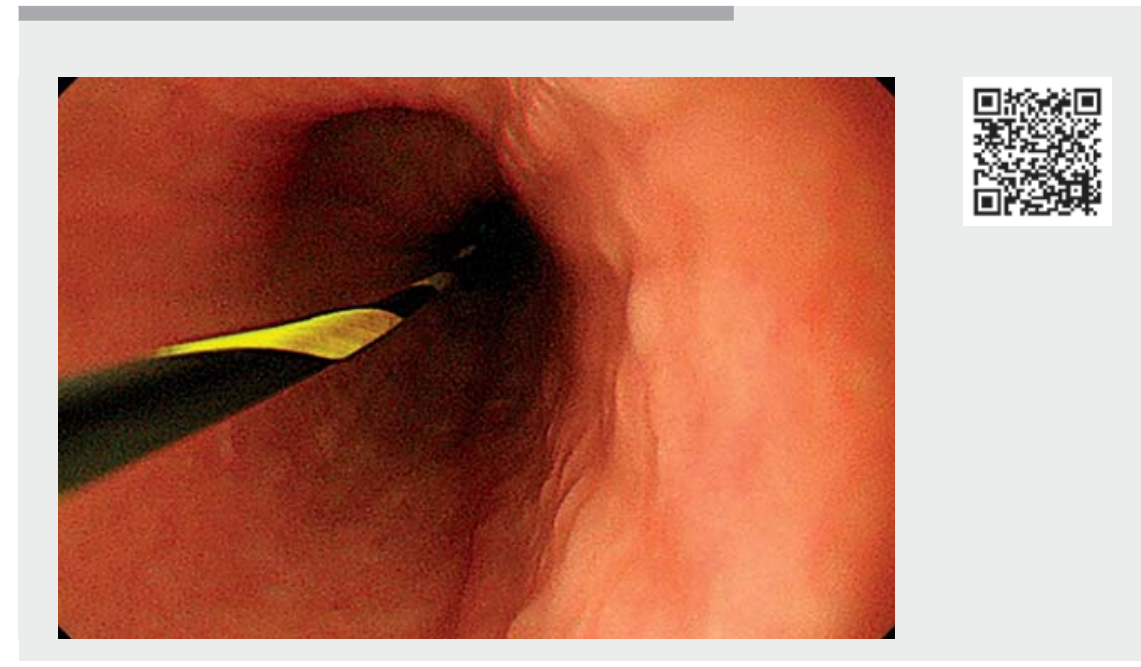

$\checkmark$ Video 1 Demonstration of guidewire-assisted technique for standard gastroscope insertion through Zenker's diverticulum for esophageal endoscopic submucosal dissection.

ticulotomy has been indicated for symptomatic Zenker's diverticulum [1,2]. In our case, the standard gastroscope could access the lesion beyond the Zenker's diverticulum, and ESD was performed without endoscopic diverticulotomy. We demonstrate a method that could be utilized for advanced endoscopy in patients with asymptomatic Zenker's diverticulum [3].

Endoscopy_UCTN_Code_TTT_1AO_2AH

\section{Competing interests}

The authors declare that they have no conflict of interest.
The authors

Kengo Kasuga ${ }^{1}$, Seiichiro Abe ${ }^{1}{ }^{\oplus}$ Ichiro Oda ${ }^{1}$, Shigetaka Yoshinaga ${ }^{1}$, Haruhisa Suzuki ${ }^{1}$, Toshio Uraoka², Yutaka Saito'

1 Endoscopy Division, National Cancer Center Hospital, Tokyo, Japan

2 Department of Gastroenterology and Hepatology, Gunma University Graduate School of Medicine, Maebashi, Japan

\section{Corresponding author}

\section{Seiichiro Abe, MD}

National Cancer Center Hospital, 5-1-1 Tsukiji, Chuo-ku, Tokyo 104-0045, Japan Fax: +81-3-3542-3815

seabe@ncc.go.jp

\section{References}

[1] Ishioka S, Sakai P, Maluf Filho F et al. Endoscopic incision of Zenker's diverticula. Endoscopy 1995; 27: 433-437

[2] Verdonck J, Morton RP. Systematic review on treatment of Zenker's diverticulum. Eur Arch Otorhinolaryngol 2015; 272: 30953107

[3] Kadish SL, Faigel DO, Long WB. Safe duodenoscopic intubation in a patient with a large Zenker's diverticulum. Gastrointest Endosc 1996; 44: 101-102

\section{Bibliography}

Endoscopy 2022; 54: E279-E280

DOI 10.1055/a-1512-8278

ISSN 0013-726X

published online 2.7.2021

(c) 2021. Thieme. All rights reserved.

Georg Thieme Verlag KG, Rüdigerstraße 14, 70469 Stuttgart, Germany

\section{ENDOSCOPY E-VIDEOS \\ https://eref.thieme.de/e-videos}

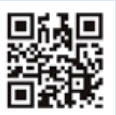

Endoscopy E-Videos is an open access online section, reporting on interesting cases and new techniques in gastroenterological endoscopy. All papers include a high quality video and all contributions are freely accessible online. Processing charges apply (currently EUR 375), discounts and wavers acc. to HINARI are available.

This section has its own submission website at

https://mc.manuscriptcentral.com/e-videos 